\title{
Cannabinoid CB1 receptor inhibition blunts adolescent-typical increased binge alcohol and sucrose consumption in male C57BL/6J mice
}

\author{
Abigail E. Agoglia a,b , Sarah E. Holstein a , Vallari R. Eastman ${ }^{\text {a }}$, Clyde W. Hodge a,b,c,d,* \\ a Bowles Center for Alcohol Studies, University of North Carolina, Chapel Hill, United States \\ b Curriculum in Neurobiology, University of North Carolina, Chapel Hill, United States \\ c Department of Psychiatry, University of North Carolina, Chapel Hill, United States \\ d Department of Pharmacology, University of North Carolina, Chapel Hill, United States
}

\section{A R T I C L E I N F O}

\section{Article history:}

Received 16 October 2015

Received in revised form 15 January 2016

Accepted 18 January 2016

Available online 19 January 2016

\section{Keywords:}

Adolescent

Alcohol drinking

Binge

Cannabinoid

CB1

AM-251

\begin{abstract}
A B S T R A C T
Increased binge alcohol consumption has been reported among adolescents as compared to adults in both humans and rodent models, and has been associated with serious long-term health consequences. However, the neurochemical mechanism for age differences in binge drinking between adolescents and adults has not been established. The present study was designed to evaluate the mechanistic role of the cannabinoid CB1 receptor in adolescent and adult binge drinking. Binge consumption was established in adolescent and adult male C57BL/6J mice by providing access to $20 \%$ alcohol or $1 \%$ sucrose for 4 h every other day. Pretreatment with the CB1 antagonist/inverse agonist AM-251 (0,1,3, and $10 \mathrm{mg} / \mathrm{kg})$ in a Latin square design dose-dependently reduced adolescent alcohol consumption to adult levels without altering adult intake. AM-251 (3 mg/kg) also reduced adolescent but not adult sucrose consumption. Adolescent reductions in alcohol and sucrose were not associated with alterations in open-field locomotor activity or thigmotaxis. These findings point to age differences in CB1 receptor activity as a functional mediator of adolescent-typical increased binge drinking as compared to adults. Developmental alterations in endocannabinoid signaling in the adolescent brain may therefore be responsible for the drinking phenotype seen in this age group.
\end{abstract}

(c) 2016 Elsevier Inc. All rights reserved.

\section{Introduction}

Adolescence, or the period between childhood and adulthood, is an evolutionarily conserved developmental period characterized by physical and behavioral changes as organisms mature. Drug use is commonly initiated during adolescence, perhaps due to the increased risk-taking, novelty-seeking and impulsive behaviors exhibited by this vulnerable age group (Crews et al., 2007; Spear, 2000). Like most drugs of abuse, alcohol use is usually initiated in adolescence (Johnston et al., 2012), and adolescent consumption of alcohol has been associated with greater risk of alcoholism over the lifespan (Dawson et al., 2008). In particular, binge drinking is more frequently reported in adolescent than adult populations (Nelson et al., 2009) and is associated with several long-term negative health consequences, including increased risk for the development of alcohol use disorders (Courtney and Polich, 2009). However, the neurobiological differences between the adolescent and adult brain that may be responsible for behavioral differences and contribute to adolescent drug use and abuse have not yet been fully characterized.

During adolescence, significant changes in brain structure, receptor density and neurotransmitter levels occur as the brain matures. In

\footnotetext{
* Corresponding author at: Bowles Center for Alcohol Studies, Thurston-Bowles Building CB \#7178, Chapel Hill, NC 27599, United States.

E-mail address: chodge@med.unc.edu (A.E. Agoglia).
}

particular, the endocannabinoid signaling systems undergoes significant structural and functional changes during adolescence in both humans and rodent models. In the human dorsal-lateral prefrontal cortex, CB1 mRNA peaks during childhood and remains high until adolescence, when it decreases to adult levels (Long et al., 2012). Similar patterns have been observed in the rat cortex with CB1 protein (Ellgren et al., 2008; Rodriguez de Fonseca et al., 1993) and mRNA (Heng et al., 2011; Van Waes et al., 2012). The endogenous ligands for the CB1 receptor, anandamide (AEA) and 2-arachidonoylglycerol (2-Ag), also experience significant flux during adolescent development, as do many of the enzymes responsible for their synthesis and degradation (Ellgren et al., 2008; Lee et al., 2013; Rubino et al., 2015; Wenger et al., 2002). These alterations in the endocannabinoid systems of the adolescent brain have a net effect of increasing CB1 inhibition of synaptic activity in juveniles and disinhibiting cortical output as the brain matures into adulthood (Heng et al., 2011). Decreased cortical control of sensorimotor brain regions has been associated with lack of inhibitory control over behavior, a behavioral characteristic of adolescence. Indeed, the cannabinoid systems have been shown to play a role in adolescent-typical behaviors. Interaction with a non-familiar social partner increases AEA levels in the adolescent rat brain (Marco et al., 2011), and inhibiting the degradation of AEA in the adolescent brain enhances social play behavior (Trezza et al., 2012). Inhibiting AEA degradation also reduces impulsive responding in an intolerance-to-delay task among maternally deprived 
rats (Marco et al., 2007). Recently, Schneider et al. demonstrated that enhanced activity of the CB1 receptor in adult rats creates adolescent-typical behavioral phenotypes, including increased novelty seeking, social interaction, impulsivity, and sensitivity to the rewarding effects of cocaine (Schneider et al., 2015). Additionally, in a human adolescent sample polymorphisms in the CNR1 gene, which encodes the CB1 receptor, were associated with self-reported impulsive behavior (Buchmann et al., 2015). Thus, the endocannabinoid systems undergo significant developmental regulation during adolescence, and may be involved in adolescenttypical behaviors that contribute to increased risk for drug use and abuse.

In studies with adult rodents and humans, a role for cannabinoid signaling in alcohol use and abuse has also been established. Acute alcohol exposure reduces $C B 1$ receptor expression in the adult mouse brain (Basavarajappa et al., 1998) and increases AEA and 2-AG concentrations in vitro (Basavarajappa and Hungund, 1999; Basavarajappa et al., 2008). CB1 receptor availability has also been shown to decrease in the cortex of human alcoholics (Ceccarini et al., 2014), and SNPs in the human CNR1 gene have been associated with alcoholism (Schmidt et al., 2002). Modulation of CB1 signaling has been shown to alter alcohol consumption in adult rodents. Pharmacological activation of CB1 has generally produced increases in alcohol self-administration (Alen et al., 2009; Linsenbardt and Boehm, 2009; Vinod et al., 2008) whereas pharmacological inactivation (Cippitelli et al., 2005; Vinod et al., 2008) and genetic deletion (Lallemand and de Witte, 2005; Racz et al., 2003) of the CB1 receptor has led to decreased alcohol intake and preference in adults (see Pava \& Woodward, 2012 for review). These studies establish the CB1 receptor as both a target of alcohol's activity in the adult brain as well as a functional modulator of alcohol consumption in rodents.

Developmental differences in the effects of cannabinoid signaling on alcohol intake have received limited investigation to date. Wang et al. (2003) compared young adult (post-natal day 42-70) and older adult (PND 182-336) CB1 knockout and wild type mice for alcohol intake and preference. Young adult CB1 knockout mice showed reduced alcohol preference and a trend for reduced intake (dose) as compared to wild type controls, whereas older adult CB1 knockout mice were not different than wild type. These results suggest that some of the regulation of alcohol consumption by CB1 activity may be age-dependent, although the study did not directly compare adolescent to adult mice. One additional study has also demonstrated that the CB1 agonist WIN 55,212-2 increased anxiety-related behaviors and increased 24-hour ethanol consumption in adolescent but not adult rats (Klugmann et al., 2011). These studies provide preliminary evidence that developmental stage may be a factor in cannabinoid-mediated alcohol consumption, but more work is needed to establish a functional role for cannabinoid regulation of adolescent alcohol consumption.

The current studies were designed to examine the effects of CB1 receptor inhibition on alcohol consumption in adolescent and adult male C57BL/6J mice, an inbred mouse strain that has been shown to consume alcohol in a binge-like manner and achieve intoxicating doses in binge models (Agoglia et al., 2015; Holstein et al., 2011). We utilized a model of binge-like alcohol consumption in order to reflect the pattern of drinking behavior most commonly reported by adolescents in the clinical literature (Courtney and Polich, 2009; Miller et al., 2007). The CB1 antagonist/ inverse agonist AM-251 was used to inhibit activity of the CB1 receptor. Additionally, we examined effects of this compound on locomotor activity, anxiety-like behavior, and consumption of the non-drug reinforcer sucrose. Our findings provide new evidence for developmental differences in sensitivity to pharmacological blockade of CB1 receptor activity, both in binge-like alcohol consumption and related behaviors.

\section{Methods}

\subsection{Subjects}

All animal procedures were carried out in accordance with the $\mathrm{NIH}$ Guide to Care and Use of Laboratory Animals (NRC, 2011) and approved by the Internal Review Board of the University of North Carolina, Chapel Hill. Male adolescent (postnatal day [PND] 21) and adult (PND $63 \pm 2$ ) C57BL/6J mice (Jackson Laboratories, Bar Harbor, ME) were housed in standard cages with a small PVC pipe for environmental enrichment. Mice were singly housed to measure individual alcohol intake, consistent with previous studies (Rhodes et al., 2005; Thiele et al., 2014). Food and water were available ad libitum in home cages except where noted. The colony room was maintained on a 12-h light/dark cycle (lights on at 20:00) at $21^{\circ} \mathrm{C}$. All experimental manipulations and testing occurred during the dark cycle.

\subsection{Drugs}

Alcohol drinking solutions ( $\mathrm{v} / \mathrm{v}$ ) were prepared by diluting $95 \%$ ethanol (Pharmco Products Inc., Brookfield, CT) with water. Sucrose drinking solutions $(\mathrm{w} / \mathrm{v})$ were prepared by dissolving sucrose in water. The CB1 antagonist/inverse agonist AM-251 (Tocris Bioscience; Ellisville, MO) was suspended in $25 \% \beta$-cyclodextrin (Sigma-Aldrich, St. Louis, $\mathrm{MO}$ ) and injected in doses of $0,1.0,3.0$ and $10.0 \mathrm{mg} / \mathrm{kg}$ i.p. with a 30 min pretreatment time. All drug solutions were freshly prepared each day of testing.

\subsection{Binge drinking procedure}

Binge drinking was established in mice as previously described (Agoglia et al., 2015; Holstein et al., 2011). All subjects ( $\mathrm{N}=36$ ) were given one week upon arrival (on experimental day 0 , see Fig. 1) at our facility to acclimate to our colony environment. During acclimation, habituation injections were administered on experimental days 4 and 6 . On experimental day 7, beginning $3 \mathrm{~h}$ into the dark cycle (10:00 AM) on PND 28 (adolescent) and 72 (adult), home cage water bottles were removed and replaced with a double ball-bearing drinking tube containing $20 \%(\mathrm{v} / \mathrm{v})$ ethanol $(\mathrm{n}=12 / \mathrm{age})$ or $1 \%(\mathrm{w} / \mathrm{v})$ sucrose $(\mathrm{n}=6 /$ age) respectively in each experiment. Drinking tubes were removed after $2 \mathrm{~h}$ of access at 12:00 PM and fluid consumption was recorded. Alcohol access was restricted to $2 \mathrm{~h}$ on the first day of drinking to avoid excessive intake that might lead to aversive effects which could limit subsequent alcohol drinking. The following day (experimental day 8), habituation injections were again administered. On experimental day 9, tubes were again placed on home cages at 10:00 AM and left in place for $4 \mathrm{~h}$ with removal at 2:00 PM. Mice had access to the tubes for $4 \mathrm{~h}$ a day, every other day, for the remainder of the experiments (Fig. 1.) Additional habituation injections were administered on an additional non-drinking day (experimental day 10) as well as $30 \mathrm{~min}$ before tube access on the two drinking days prior to drug testing (experimental days 11 and 13) for a total of six days of habituation injections in all, two on drinking days and four on non-drinking days.

Beginning on PND 36/80, each drinking session was preceded by an injection of AM-251 or vehicle. The alcohol drinking experiment utilized a Latin square design to test four doses of AM-251 (0, 1.0, 3.0 and $10.0 \mathrm{mg} / \mathrm{kg}$ ) within subjects. The sucrose drinking experiments tested the lowest effective dose of AM-251 in the alcohol experiment $(3.0 \mathrm{mg} / \mathrm{kg})$ in a between-subjects design.

\subsection{Locomotor testing}

Following the completion of alcohol drinking, on PND 44 (adolescent) or PND 88 (adult) mice were injected with either vehicle or AM251 ( $1 \mathrm{mg} / \mathrm{kg}, 30$-min pretreatment) prior to a locomotor activity test ( $n=6 /$ treatment/age). Open field activity was measured in Plexiglas activity monitor chambers $\left(27.9 \mathrm{~cm}^{2}\right.$; ENV-510, Med Associates, Georgia, VT) connected to computers for data collection (Hodge et al., 1999; Stevenson et al., 2008). Two sets of 16 pulse-modulated infrared photobeams were located on opposite walls and recorded X-Y ambulatory movements. The mouse's position in the open field was assessed every $100 \mathrm{~ms}$ to quantify distance traveled (in meters). 
A DAY $0 \quad 7$ $7 \quad 15$ $15 \quad 21 \quad 23$

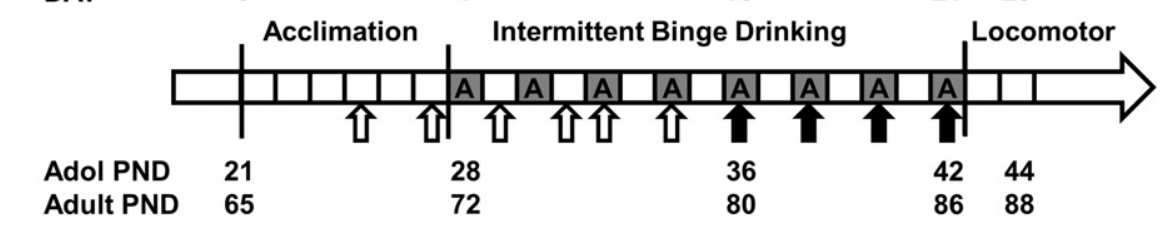

$B_{\text {DAY }}$ DAY 0 7 15
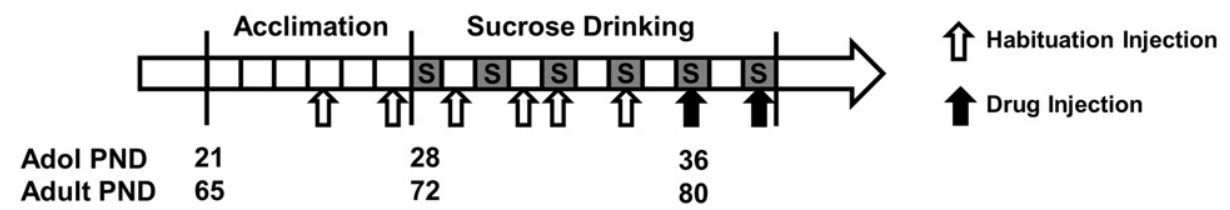

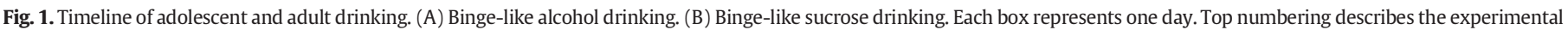

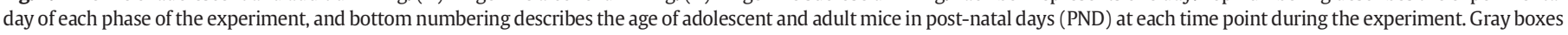

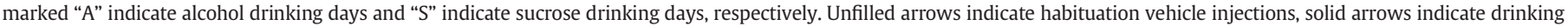
sessions preceded by a drug injection.

\subsection{Data analysis}

Alcohol intake data were reported as grams of alcohol per kilogram of body weight and sucrose intake data were reported as milliliters of fluid consumed per kilogram of body weight. One adolescent mouse in the alcohol drinking experiment was excluded from the analysis due to consistently low levels of alcohol intake ( $<1 \mathrm{~g} / \mathrm{kg}$ in $4 \mathrm{~h}$ ). Alcohol intake data were analyzed via two-way repeated measures ANOVA (Age $\times$ Dose) with one-way repeated measures ANOVA separately within age groups as planned comparisons. Holm-Sidak's multiple comparisons test was used for all post-hoc analyses. Sucrose intake was analyzed via Student's t-test. Open field locomotor data were collapsed into 20 min time bins and activity was assessed via two-way repeated measures ANOVA (Dose $\times$ Time) separately within each age. Locomotor data were further analyzed for potential age or druginduced differences in anxiety-like behavior in an open-field test. Thigmotaxis was evaluated by comparing distance $(\mathrm{cm})$ traveled in the center zone (inner $25 \%$ of the area) to distance traveled in the periphery (outer $75 \%$ of the area) as previously described (Agoglia et al., 2015; Hodge et al., 2002). $\alpha$ was set at 0.05 for all comparisons. All analyses were performed using Prism v. 6.0 (GraphPad, La Jolla, CA).

\section{Results}

\subsection{Baseline drinking and body weight}

Adolescent alcohol consumption averaged $3.88 \mathrm{~g} / \mathrm{kg}$ and adult intake averaged $3.99 \mathrm{~g} / \mathrm{kg}$ over the four-hour drinking session prior to drug testing (Table 1). Sucrose consumption averaged $97.64 \mathrm{~mL} / \mathrm{kg}$ in adolescents and $82.71 \mathrm{~mL} / \mathrm{kg}$ in adults. No significant age differences in consumption prior to drug administration emerged ( $p>0.05$ for all comparisons). To test for potential age differences in injection stress, alcohol intake on experimental day 9 (no injection) was compared to alcohol intake on experimental day 11 (vehicle habituation injection 30 min prior to drinking) separately within each age group. In both adolescents and adults, no differences in alcohol consumption were observed between days 9 and 11 ( $p>0.05$ for both comparisons, data not shown.) Additionally, body weight measurements taken before drug administration and after four days of repeated drug administration were compared for adolescents and adults. Adolescent body weight increased significantly over days and adult body weight did not change between measurements (Table 2), with both ages showing body weights similar to those reported previously (Agoglia et al., 2015) indicating no major adverse effects of drug treatment.

\subsection{Effect of CB1 inhibition on binge-like alcohol drinking}

Following a 30 minute pretreatment with the CB1 receptor antagonist/inverse agonist AM-251, a significant main effect of Age emerged, $F(1,21)=5.52, p<0.05$. A main effect of Dose was also observed, $F$ $(3,63)=16.86, p<0.0001$. In adolescent mice, a planned one-way ANOVA revealed a main effect of Dose, $F(2.46)=7.67, p<0.01$. Holm-Sidak's multiple comparisons test revealed that the $1.0 \mathrm{mg} / \mathrm{kg}$ ,3.0 mg/kg and $10 \mathrm{mg} / \mathrm{kg}$ doses significantly reduced alcohol consumption in adolescent mice (Fig. 2A). In adult mice, an effect of Dose was also significant $[F(2.23)=8.87, p<0.0001]$. However, Holm-Sidak's multiple comparisons test indicated that only the $10.0 \mathrm{mg} / \mathrm{kg}$ dose of AM-251 significantly reduced alcohol consumption in adult mice (Fig. 2B) indicating age-dependent differences in dose sensitivity. Direct comparison of adolescent intake at the lowest effective dose $(1.0 \mathrm{mg} / \mathrm{kg})$ and adult intake under vehicle conditions failed to find significant differences, indicating that adolescent alcohol intake had been reduced to adult levels at this dose $[t(21)=0.086, p>0.05]$.

\subsection{Effect of CB1 receptor inhibition on binge-like sucrose drinking}

To determine if the effects of the CB1 antagonist/inverse agonist AM251 were selective for alcohol consumption, or representative of effects on other reinforcing solutions, adolescent and adult mice were pretreated with the lowest effective dose of AM-251 $(3.0 \mathrm{mg} / \mathrm{kg})$ prior to a four-hour sucrose consumption test. AM-251 pretreatment significantly reduced sucrose consumption in adolescent mice $[t(5)=3.30$, $p<0.05$, Fig. 2C] but failed to significantly alter sucrose drinking in adult mice ( $p>0.05$, Fig. 2D). Direct comparison of adolescent sucrose

Table 1

Baseline alcohol intake in adolescent and adult mice. Mean alcohol consumption in grams of alcohol per kilogram of bodyweight $( \pm$ SEM) of adolescent and adult mice on the three drinking days prior to drug testing. No Inj. indicates drinking days without injections, and Hab. Inj. indicates drinking days preceded by habituation injections.

\begin{tabular}{llll}
\hline \multirow{2}{*}{ Age } & \multicolumn{2}{l}{ Alcohol Intake $(\mathrm{g} / \mathrm{kg})$} & \\
\cline { 2 - 4 } & Day 9 (No Inj.) & Day 11 (Hab. Inj.) & Day 13 (Hab. Inj.) \\
\hline Adolescent & $3.60 \pm 0.46$ & $3.80 \pm 0.51$ & $4.11 \pm 0.35$ \\
Adult & $4.27 \pm 0.38$ & $4.36 \pm 0.31$ & $4.67 \pm 0.28$ \\
\hline
\end{tabular}


Table 2

Effect of CB1 inhibition on body weight. Mean body weight $( \pm$ SEM) of adolescent (postnatal day [PND] 34) and adult mice (PND 78) before and after administration of the CB1 antagonist/inverse agonist AM-251 (PND 42/86, respectively).

\begin{tabular}{lcclcll}
\hline & \multicolumn{2}{l}{ Before AM-251 } & & \multicolumn{2}{l}{ After AM-251 } \\
\cline { 2 - 3 } \cline { 5 - 6 } \cline { 5 - 6 } & Age (PND) & Body-weight $(\mathrm{g})$ & & Age (PND) & Body-weight (g) \\
\hline Adolescent & 34 & $20.02 \pm 0.28$ & & 42 & $22.91 \pm 0.30$ \\
Adult & 78 & $25.27 \pm 0.36$ & & 86 & $26.72 \pm 0.43$ \\
\hline
\end{tabular}

intake with AM-251 pretreatment and adult intake under vehicle conditions failed to find significant differences, indicating that adolescent sucrose intake had been reduced to adult levels $[t(10)=0.34$, $p>0.05]$.

\subsection{Effect of CB1 receptor inhibition on open-field locomotor activity}

To determine if the effects of CB1 inhibition with AM-251 were associated with alterations in general locomotor behavior, adolescent and adult mice were pretreated with the lowest effective dose of AM$251(1.0 \mathrm{mg} / \mathrm{kg}) 30 \mathrm{~min}$ prior to a two hour open-field locomotor behavior assay. In adolescent mice, AM-251 pretreatment failed to alter locomotor activity ( $p>0.05$, Fig. 3A). However, in adult mice AM-251 pretreatment resulted in a significant main effect of dose, $F(1,10)=$ $5.16, p<0.05$ (Fig. 3B), suggesting that the $1.0 \mathrm{mg} / \mathrm{kg}$ dose of AM-251 reduced locomotor activity in adults but not adolescents.

To determine whether pretreatment with AM-251 was associated with alterations in anxiety-like behaviors, adolescent and adult mice were evaluated for thigmotaxis during the open-field locomotor testing. Both adolescents (Fig. 3C) and adults (Fig. 3D) spent approximately $20 \%$ of the session in the center of the open field, and neither age displayed any alterations in time spent in the center following AM-251 pretreatment $(p>0.05)$. Additionally, a direct comparison of vehicle-treated adolescent and adult mice failed to show any age differences in thigmataxis $[F(1,10)=0.26, p>0.05$; data not shown.]

A

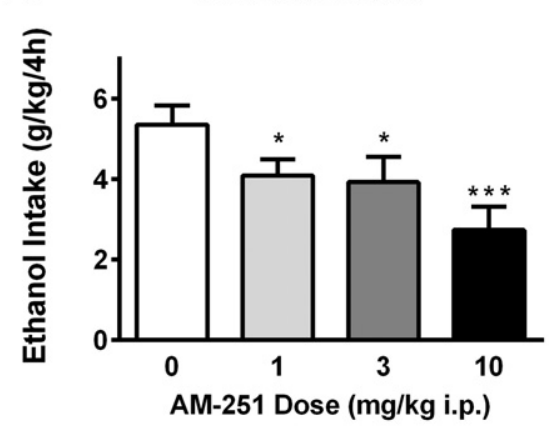

C

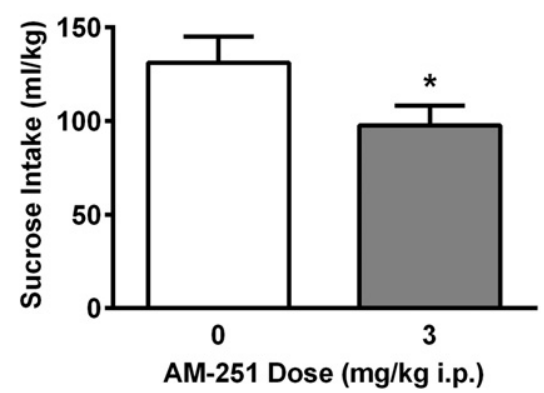

\section{Discussion}

The endocannabinoid CB1 receptor is the most abundant G proteincoupled receptor in the mammalian brain (Marsicano and Lutz, 1999), and has been shown to play a critical role in both neuronal development (Gaffuri et al., 2012) and reward-related behaviors (Panagis et al., 2014). However, the specific regulation of alcohol consumption by cannabinoid signaling during the adolescent developmental period has not yet been reported. Here, we show that the CB1 receptor antagonist/inverse agonist AM-251 reduces binge-like alcohol and sucrose consumption in male C57BL/6J mice. However, adolescent mice were more sensitive than adults to this effect, displaying reductions in alcohol and sucrose drinking following AM-251 (1 or $3 \mathrm{mg} / \mathrm{kg}$ ); doses that were ineffective at modulating intake in adults. We further report reduced sensitivity to the locomotor effects of AM-251 in adolescent mice, but no age or drug differences in thigmotaxis following AM-251 pretreatment. Together, these findings provide evidence of differential sensitivity to pharmacological manipulation of the CB1 receptor in adolescent and adult mice, and point to endocannabinoid signaling as a possible mechanism for age differences in alcohol consumption.

The drinking model employed in the present experiments resulted in significant age differences in alcohol and sucrose consumption such that adolescent mice consumed more alcohol $\mathrm{g} / \mathrm{kg}$ and sucrose $\mathrm{mL} / \mathrm{kg}$ than adult mice. This finding is in agreement with previous reports of greater alcohol and sucrose consumption among adolescent rodents (Agoglia et al., 2015; Brunell and Spear, 2005; Maldonado et al., 2008). Data from surveys of human alcohol users suggest that alcohol use is usually initiated during adolescence, and adolescent alcohol intake has also been reported to be higher than adult intake using human subjects (Courtney and Polich, 2009; Harford et al., 2005; Johnston et al., 2012). Thus, the drinking method employed in the present studies appears to be an appropriate model of adolescent-typical binge drinking. Although we did not assess blood alcohol levels in the present experiments, previous reports from our lab have demonstrated that both adolescent and adult mice achieve binge levels of blood

\section{B}

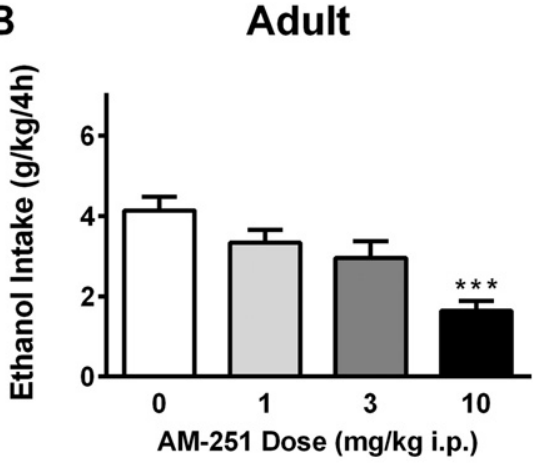

D Adult

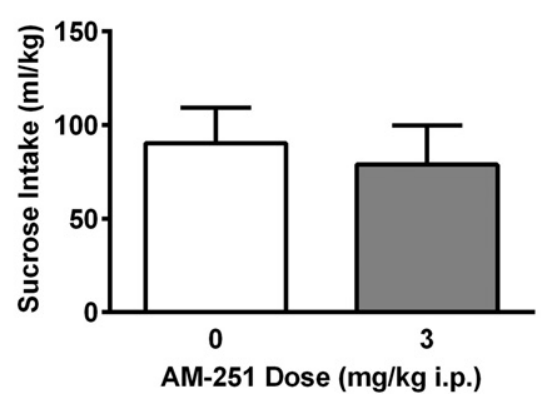

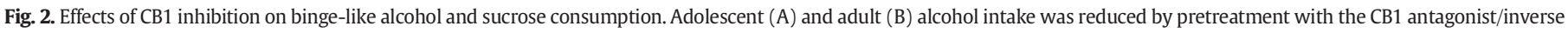

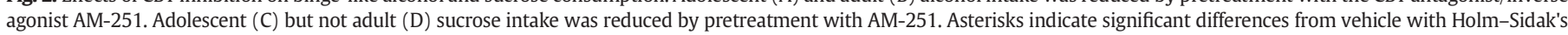
multiple comparisons test/Student's t-test, ${ }^{*} p<0.05$, ${ }^{* * *} p<0.001$. 
A

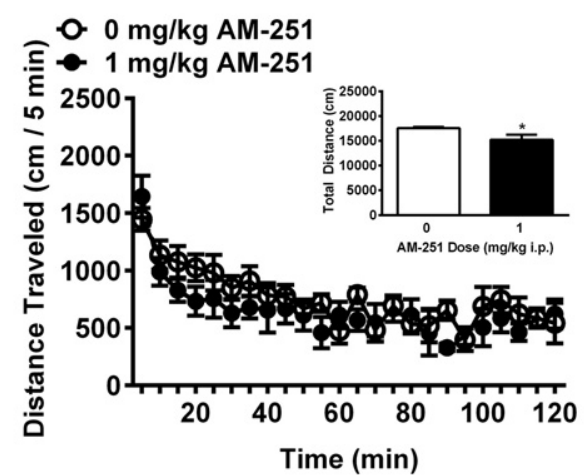

c

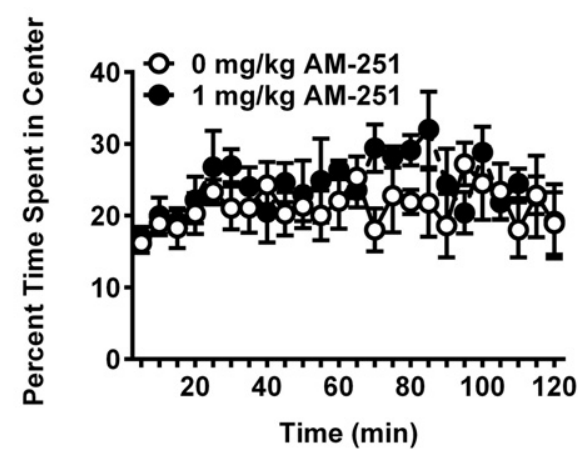

B

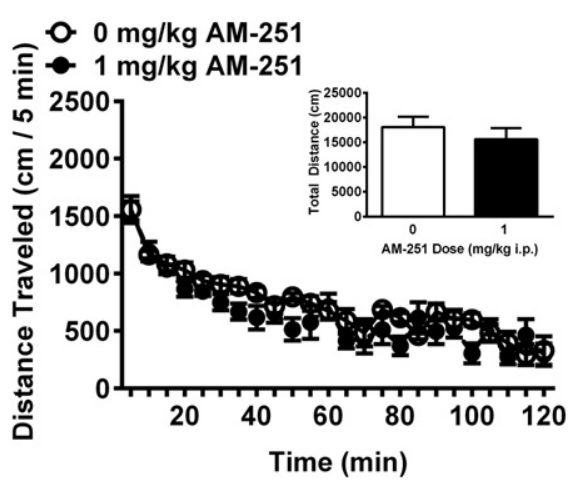

D

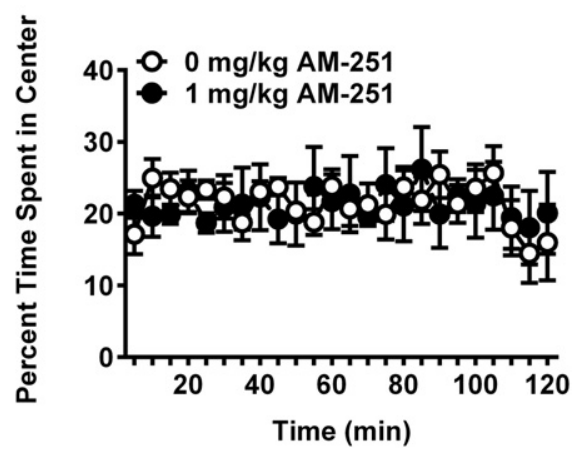

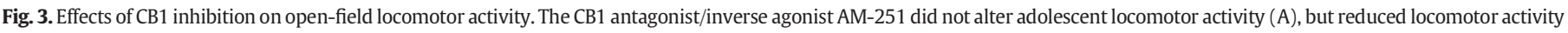

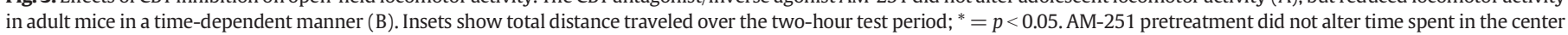
of the open field in either adolescents or adults ( $C$ and D).

alcohol concentration ( $>80 \mathrm{mg} / \mathrm{dL}$ ) in this limited access procedure (Agoglia et al., 2015; Holstein et al., 2011).

Pretreatment with the CB1 antagonist /inverse agonist AM-251 suggested increased sensitivity to cannabinoid modulation in adolescent as compared to adult mice, with all doses tested $(1,3$ and $10 \mathrm{mg} / \mathrm{kg}$ ) reducing alcohol consumption in adolescents, whereas only the high dose $(10 \mathrm{mg} / \mathrm{kg})$ reduced alcohol consumption in adults. Adolescent alcohol consumption was reduced by $28 \%$, from $5.4 \mathrm{~g} / \mathrm{kg}$ to $3.9 \mathrm{~g} / \mathrm{kg}$, at the $1 \mathrm{mg} / \mathrm{kg}$ dose. Notably, this reduction in alcohol consumption brought adolescent intake to the level of untreated adult mice, who averaged $4.1 \mathrm{~g} / \mathrm{kg}$ under vehicle conditions. The effect at this dose appears to be selective for the excessive alcohol consumption exhibited by adolescents, as adult alcohol intake was not significantly reduced at this dose. Adolescent sucrose consumption was also reduced to adult levels after pretreatment with the $3 \mathrm{mg} / \mathrm{kg}$ dose of AM-251. Adolescent sucrose intake decreased from $131.1 \mathrm{~mL} / \mathrm{kg}$ under vehicle conditions to $97.6 \mathrm{~mL} / \mathrm{kg}$ after $3 \mathrm{mg} / \mathrm{kg}$ of AM-251, putting adolescent intake in line with average adult sucrose intake $(90.2 \mathrm{~mL} / \mathrm{kg})$. Consistent with the alcohol experiments, $3 \mathrm{mg} / \mathrm{kg}$ AM-251 did not significantly reduce adult sucrose consumption. Thus, inhibition of the CB1 receptor with AM251 appears to blunt the adolescent-typical phenotype of increased binge alcohol and sucrose drinking and bring adolescent consumption to a more moderate adult-like level. This finding points to activity of the $\mathrm{CB} 1$ receptor as a mediator of the increased alcohol and sucrose consumption typically displayed by adolescents as compared to adults.

Decreases in alcohol consumption may also be due to alterations in alcohol metabolism as a result of AM-251 treatment. We did not assess blood alcohol concentration in the present experiments, nor have any previous studies determined the effects of AM-251 on alcohol metabolism. However, the CB1 receptor inverse agonist/antagonist SR141716A has a similar mechanism of action as AM-251 and induces similar decreases in alcohol consumption. Previous studies have found that SR141716A pretreatment does not alter blood alcohol concentration in rats (Lallemand et al., 2001; Serra et al., 2001). These previous reports make actions of AM-251 on alcohol metabolism less likely. However, in future studies it will be important to assess blood alcohol levels with and without AM-251 pretreatment to definitively address this question.

Adult mice displayed a reduction in open-field locomotor activity following pretreatment with $1.0 \mathrm{mg} / \mathrm{kg} \mathrm{AM}-251$. Therefore, the reduction in adult alcohol consumption at the $10 \mathrm{mg} / \mathrm{kg}$ dose should be considered in light of potential gross locomotor effects and not specific effects on alcohol drinking. In contrast, adolescent mice did not show any effect of AM-251 pretreatment on open-field locomotor activity. This finding indicates additional age differences in the behavioral effects of CB1 receptor inhibition, as adolescents appear to have reduced sensitivity to the locomotor effects of AM-251. Additionally, modulation of CB1 activity has been shown to alter anxiety-related behaviors, and age differences in sensitivity to the anxiogenic effects of CB1 activation in adolescents and adults have been reported (Klugmann et al., 2011). The current experiments failed to detect any effect of AM-251 on thigmotaxis in either adolescents or adults. This result suggests that the age differences in the effects of AM-251 on alcohol and sucrose consumption are likely independent of any anxiety-related effect of this drug as measured by the open-field thigmotaxy assay. Injection itself is a potential stressor, and adolescents have been shown to be more sensitive to some stressors than adults (Spear, 2000). We therefore compared adolescent and adult alcohol intake on a day without injections (experimental day 9) and a day with vehicle injection prior to drinking (experimental day 11). No differences in alcohol intake between days emerged in either age group, suggesting that injection stress was not significantly different between ages. Additionally, we compared adolescent and adult mice treated with vehicle injections directly in the openfield locomotor activity assay. No age differences in thigmataxis 
emerged, indicating that adolescents did not display greater anxietylike behavior than adults after injection.

The effects of the CB1 antagonist/inverse agonist AM-251 on alcohol drinking reported here are reminiscent of those observed by Wang et al. (2003), who found that pretreatment with the CB1 antagonist/inverse agonist SR141716A reduced alcohol consumption in young adults but not older mice. Further, in the present study, adolescents were sensitive to an AM-251-induced decrease in sucrose consumption whereas adults showed no effect of AM-251 pretreatment, indicating that the effects of CB1 inhibition in adolescents reduced consumption of reinforcing solutions generally. The relationship between age differences in behavioral effects of CB1 inhibition and the altered expression of the $\mathrm{CB} 1$ receptor in the adolescent brain remains unclear. Adolescents display increased CB1 receptor expression, which may reduce sensitivity to CB1 modulation owing to the greater number of receptors needed to be occupied achieve a significant proportion of activation; i.e. a higher dose of AM251 would be predicted to be necessary in adolescents to reach behavioral significance. In contrast, we observed increased behavioral sensitivity of adolescent mice to CB1 inhibition, which may be explained by receptor "spareness", or increased efficacy of the compound in adolescent mice, leading to behavioral effects despite a smaller proportion of occupied receptors (Rang, 2006). The underlying biology of the adolescent endocannabinoid system contributing to this increased sensitivity to AM-251 is likewise unknown. However, adolescent mice have been shown to have altered functional coupling between the CB1 receptor and $G$ proteins as compared with adult mice (Moore et al., 2010; Wang et al., 2003), which is a plausible explanation for age differences in sensitivity to CB1 inhibition. Although previous reports have shown that $\mathrm{G}$ protein expression reaches adult levels in the mouse cortex by PND 25 (Ihnatovych et al., 2002), age differences in CB1 receptor trafficking to the plasma membrane or the influence of CB1 accessory proteins could explain differences in functional coupling of CB1 in adolescents and adults. Direct manipulation of the CB1 receptor in the adolescent brain using genetic or pharmacological strategies would help to clarify the molecular mechanism driving the age differences in sensitivity to CB1 antagonism/inverse agonism.

The CB1 receptor is involved in appetite and consummatory behaviors (Jager and Witkamp, 2014), and previous studies have reported decreases in body weight following pretreatment with the cannabinoid antagonist/inverse agonist AM-251 (Merroun et al., 2013). The withinsubjects design of the present studies made drug effects on body weight more difficult to detect, owing to the lack of completely untreated mice for comparison. However, body weights of adolescent and adult mice were compared prior to drug treatment and after four days of repeated administration of AM-251. Adolescent body weight increased in a normal developmental trajectory (Agoglia et al., 2015), and adult body weight remained unchanged before and after treatment with either drug. The relatively short exposure period and lower doses used in the present experiments do not appear to alter body weight in adolescent or adult mice. We also did not observe gross developmental defects in adolescent mice treated with AM-251 as indexed by normal body weight and locomotor activity in an open field.

In summary, the current study provides evidence of altered behavioral sensitivity to pharmacological inhibition of the $\mathrm{CB} 1$ receptor in adolescent mice. Administration of the CB1 antagonist/inverse agonist AM-251 reduced binge alcohol and sucrose consumption in both adolescent and adult mice. However, adolescent alcohol and sucrose consumption were reduced at all doses tested, and intake of both solutions decreased to adult levels. Adult alcohol and sucrose intake were reduced only at the highest dose, and adults displayed reductions in locomotor activity absent in adolescent mice. These experiments provide new evidence for age differences in the behavioral pharmacology of the CB1 signaling systems, which may be due to well-characterized alterations in the CB1 systems during adolescent brain development. Further, these findings point to developmental differences in CB1 signaling as a potential regulator of age differences in the consumption of reinforcing solutions. Mechanistic studies aimed at the brain regions responsible for these age differences and the long-term consequences of adolescent alcohol exposure would definitively establish a role for cannabinoid signaling in the adolescent brain on alcohol.

\section{Acknowledgments}

This research was supported by grants R37AA014983 and P60AA011065 to CWH, and 1F31AA024375-01 to AEA.

\section{References}

Agoglia, A.E., Holstein, S.E., Reid, G., Hodge, C.W., 2015. CaMKIIalpha-GluA1 activity underlies vulnerability to adolescent binge alcohol drinking. Alcohol. Clin. Exp. Res. 39 (9), 1680-1690.

Alen, F., Santos, A., Moreno-Sanz, G., Gonzalez-Cuevas, G., Gine, E., Franco-Ruiz, L., et al. 2009. Cannabinoid-induced increase in relapse-like drinking is prevented by the blockade of the glycine-binding site of N-methyl-D-aspartate receptors. Neuroscience 158 (2), 465-473.

Basavarajappa, B.S., Cooper, T.B., Hungund, B.L., 1998. Chronic ethanol administration down-regulates cannabinoid receptors in mouse brain synaptic plasma membrane. Brain Res. 793 (1-2), 212-218.

Basavarajappa, B.S., Hungund, B.L., 1999. Chronic ethanol increases the cannabinoid receptor agonist anandamide and its precursor $\mathrm{N}$-arachidonoylphosphatidylethanolamine in SK-N-SH cells. J. Neurochem. 72 (2), 522-528.

Basavarajappa, B.S., Ninan, I., Arancio, O., 2008. Acute ethanol suppresses glutamatergic neurotransmission through endocannabinoids in hippocampal neurons. J. Neurochem. 107 (4), 1001-1013.

Brunell, S.C., Spear, L.P., 2005. Effect of stress on the voluntary intake of a sweetened ethanol solution in pair-housed adolescent and adult rats. Alcohol. Clin. Exp. Res. 29 (9), 1641-1653.

Buchmann, A.F., Hohm, E., Witt, S.H., Blomeyer, D., Jennen-Steinmetz, C., Schmidt, M.H., et al., 2015. Role of CNR1 polymorphisms in moderating the effects of psychosocial adversity on impulsivity in adolescents. J. Neural Transm. 122 (3), 455-463.

Ceccarini, J., Hompes, T., Verhaeghen, A., Casteels, C., Peuskens, H., Bormans, G., et al., 2014. Changes in cerebral CB1 receptor availability after acute and chronic alcohol abuse and monitored abstinence. J. Neurosci. 34 (8), 2822-2831.

Cippitelli, A., Bilbao, A., Hansson, A.C., del Arco, I., Sommer, W., Heilig, M., et al., 2005. Cannabinoid CB1 receptor antagonism reduces conditioned reinstatement of ethanolseeking behavior in rats. Eur. J. Neurosci. 21 (8), 2243-2251.

Courtney, K.E., Polich, J., 2009. Binge drinking in young adults: data, definitions, and determinants. Psychol. Bull. 135 (1), 142-156.

Crews, F., He, J., Hodge, C., 2007. Adolescent cortical development: a critical period of vulnerability for addiction. Pharmacol. Biochem. Behav. 86 (2), 189-199.

Dawson, D.A., Goldstein, R.B., Chou, S.P., Ruan, W.J., Grant, B.F., 2008. Age at first drink and the first incidence of adult-onset DSM-IV alcohol use disorders. Alcohol. Clin. Exp. Res. 32 (12), 2149-2160.

Ellgren, M., Artmann, A., Tkalych, O., Gupta, A., Hansen, H.S., Hansen, S.H., et al., 2008. Dynamic changes of the endogenous cannabinoid and opioid mesocorticolimbic systems during adolescence: THC effects. Eur. Neuropsychopharmacol. 18 (11) $826-834$.

Gaffuri, A.L., Ladarre, D., Lenkei, Z., 2012. Type-1 cannabinoid receptor signaling in neuronal development. Pharmacology 90 (1-2), 19-39.

Harford, T.C., Grant, B.F., Yi, H.Y., Chen, C.M., 2005. Patterns of DSM-IV alcohol abuse and dependence criteria among adolescents and adults: results from the 2001 National Household Survey on Drug Abuse. Alcohol. Clin. Exp. Res. 29 (5), 810-828.

Heng, L., Beverley, J.A., Steiner, H., Tseng, K.Y., 2011. Differential developmental trajectories for CB1 cannabinoid receptor expression in limbic/associative and sensorimotor cortical areas. Synapse 65 (4), 278-286.

Hodge, C.W., Mehmert, K.K., Kelley, S.P., McMahon, T., Haywood, A., Olive, M.F., et al., 1999. Supersensitivity to allosteric GABA(A) receptor modulators and alcohol in mice lacking PKCepsilon. Nat. Neurosci. 2 (11), 997-1002.

Hodge, C.W., Raber, J., McMahon, T., Walter, H., Sanchez-Perez, A.M., Olive, M.F., et al., 2002. Decreased anxiety-like behavior, reduced stress hormones, and neurosteroid supersensitivity in mice lacking protein kinase Cepsilon. J. Clin. Invest. 110 (7), 1003-1010.

Holstein, S.E., Spanos, M., Hodge, C.W., 2011. Adolescent C57BL/6J mice show elevated alcohol intake, but reduced taste aversion, as compared to adult mice: a potential behavioral mechanism for binge drinking. Alcohol. Clin. Exp. Res. 35 (10), 1842-1851.

Ihnatovych, I., Novotny, J., Haugvicova, R., Bourova, L., Mares, P., Svoboda, P., 2002. Opposing changes of trimeric $G$ protein levels during ontogenetic development of rat brain. Brain Res. Dev. Brain Res. 133 (1), 57-67.

Jager, G., Witkamp, R.F., 2014. The endocannabinoid system and appetite: relevance for food reward. Nutr. Res. Rev. 27 (1), 172-185.

Johnston, L.D.O.P., Bachman, J.G., Schulenberg, J.E., 2012. Monitoring the Future: National Survey Results on Drug use, 1975-2011: vol. I: Secondary School Students. Ann Arbor: Institute for Social Research, The University of Michigan, p. 760.

Klugmann, M., Klippenstein, V., Leweke, F.M., Spanagel, R., Schneider, M., 2011. Cannabinoid exposure in pubertal rats increases spontaneous ethanol consumption and NMDA receptor associated protein levels. Int. J. Neuropsychopharmacol. 14 (4), 505-517.

Lallemand, F., de Witte, P., 2005. Ethanol induces higher BEC in CB1 cannabinoid receptor knockout mice while decreasing ethanol preference. Alcohol Alcohol. 40 (1), 54-62. 
Lallemand, F., Soubrie, P.H., De Witte, P.H., 2001. Effects of CB1 cannabinoid receptor blockade on ethanol preference after chronic ethanol administration. Alcohol. Clin. Exp. Res. 25 (9), 1317-1323.

Lee, T.T., Hill, M.N., Hillard, C.J., Gorzalka, B.B., 2013. Temporal changes in Nacylethanolamine content and metabolism throughout the peri-adolescent period. Synapse 67 (1), 4-10.

Linsenbardt, D.N., Boehm 2nd, S.L., 2009. Agonism of the endocannabinoid system modulates binge-like alcohol intake in male C57BL/6J mice: involvement of the posterior ventral tegmental area. Neuroscience 164 (2), 424-434.

Long, L.E., Lind, J., Webster, M., Weickert, C.S., 2012. Developmental trajectory of the endocannabinoid system in human dorsolateral prefrontal cortex. BMC Neurosci. 13,87

Maldonado, A.M., Finkbeiner, L.M., Alipour, K.K., Kirstein, C.L., 2008. Voluntary ethano consumption differs in adolescent and adult male rats using a modified sucrosefading paradigm. Alcohol. Clin. Exp. Res. 32 (9), 1574-1582.

Marco, E.M., Adriani, W., Canese, R., Podo, F., Viveros, M.P., Laviola, G., 2007. Enhancement of endocannabinoid signalling during adolescence: modulation of impulsivity and ong-term consequences on metabolic brain parameters in early maternally deprived rats. Pharmacol. Biochem. Behav. 86 (2), 334-345.

Marco, E.M., Rapino, C., Caprioli, A., Borsini, F., Maccarrone, M., Laviola, G., 2011. Social en counter with a novel partner in adolescent rats: activation of the central endocannabinoid system. Behav. Brain Res. 220 (1), 140-145.

Marsicano, G., Lutz, B., 1999. Expression of the cannabinoid receptor CB1 in distinct neuronal subpopulations in the adult mouse forebrain. Eur. J. Neurosci. 11 (12) 4213-4225.

Merroun, I., Sanchez-Gonzalez, C., Martinez, R., Lopez-Chaves, C., Porres, J.M., Aranda, P. et al., 2013. Novel effects of the cannabinoid inverse agonist AM 251 on parameters related to metabolic syndrome in obese Zucker rats. Metabolism 62 (11), 1641-1650.

Miller, J.W. Naimi, T.S., Brewer, R.D. Jones, S.E. 2007. Binge drinking and associated health risk behaviors among high school students. Pediatrics 119 (1), 76-85.

Moore, N.L., Greenleaf, A.L., Acheson, S.K., Wilson, W.A., Swartzwelder, H.S., Kuhn, C.M. 2010. Role of cannabinoid receptor type 1 desensitization in greater tetrahydrocannabinol impairment of memory in adolescent rats. J. Pharmacol. Exp. Ther. 335 (2), 294-301.

National Research Council (US) Committee for the Update of the Guide for the Care and Use of Laboratory Animals, 2011. Guide for the Care and Use of Laboratory Animals. 8th. National Academies Press (US), Washington (DC). Available from: http://www ncbi.nlm.nih.gov/books/NBK54050/.

Nelson, D.E., Naimi, T.S., Brewer, R.D., Nelson, H.A., 2009. State alcohol-use estimates among youth and adults, 1993-2005. Am. J. Prev. Med. 36 (3), 218-224.

Panagis, G., Mackey, B., Vlachou, S., 2014. Cannabinoid regulation of brain reward processing with an emphasis on the role of CB1 receptors: a step back into the future. Front Psychiatry 5, 92.

Pava, M.J., Woodward, J.J., 2012. A review of the interactions between alcohol and the endocannabinoid system: implications for alcohol dependence and future directions for research. Alcohol 46 (3), 185-204.
Racz, I., Bilkei-Gorzo, A., Toth, Z.E., Michel, K., Palkovits, M., Zimmer, A., 2003. A critical role for the cannabinoid $\mathrm{CB} 1$ receptors in alcohol dependence and stress-stimulated ethanol drinking. J. Neurosci. 23 (6), 2453-2458.

Rang, H.P., 2006. The receptor concept: pharmacology's big idea. Br. J. Pharmacol. 147 (Suppl. 1), S9-16.

Rhodes, J.S., Best, K., Belknap, J.K., Finn, D.A., Crabbe, J.C., 2005. Evaluation of a simple model of ethanol drinking to intoxication in C57BL/6J mice. Physiol. Behav. 84 (1), $53-63$.

Rodriguez de Fonseca, F., Ramos, J.A., Bonnin, A., Fernandez-Ruiz, J.J., 1993. Presence of cannabinoid binding sites in the brain from early postnatal ages. Neuroreport 4 (2), $135-138$.

Rubino, T., Prini, P., Piscitelli, F., Zamberletti, E., Trusel, M., Melis, M., et al., 2015. Adolescent exposure to THC in female rats disrupts developmental changes in the prefrontal cortex. Neurobiol. Dis. 73, 60-69.

Schmidt, L.G., Samochowiec, J. Finckh, U. Fiszer-Piosik, E., Horodnicki, J. Wendel, B, et al. 2002. Association of a CB1 cannabinoid receptor gene (CNR1) polymorphism with severe alcohol dependence. Drug Alcohol Depend. 65 (3), 221-224.

Schneider, M., Kasanetz, F., Lynch, D.L., Friemel, C.M., Lassalle, O., Hurst, D.P., et al., 2015. Enhanced functional activity of the cannabinoid type-1 receptor mediates adolescent behavior. J. Neurosci. 35 (41), 13975-13988.

Serra, S., Carai, M.A., Brunetti, G., Gomez, R., Melis, S., Vacca, G., et al., 2001. The cannabinoid receptor antagonist SR 141716 prevents acquisition of drinking behavior in alcohol-preferring rats. Eur. J. Pharmacol. 430 (2-3), 369-371.

Spear, L.P., 2000. The adolescent brain and age-related behavioral manifestations. Neurosci. Biobehav. Rev. 24 (4), 417-463.

Stevenson, R.A., Besheer, J., Hodge, C.W., 2008. Comparison of ethanol locomotor sensitization in adolescent and adult DBA/2J mice. Psychopharmacology 197 (3), 361-370.

Thiele, T.E., Crabbe, J.C., Boehm 2nd, S.L., 2014. "Drinking in the Dark" (DID): a simple mouse model of binge-like alcohol intake. Curr. Protoc. Neurosci. 68 (9), 49 41-49 49 (12).

Trezza, V., Damsteegt, R., Manduca, A., Petrosino, S., Van Kerkhof, L.W., Pasterkamp, R.J., et al., 2012. Endocannabinoids in amygdala and nucleus accumbens mediate social play reward in adolescent rats. J. Neurosci. 32 (43), 14899-14908.

Van Waes, V., Beverley, J.A., Siman, H., Tseng, K.Y., Steiner, H., 2012. CB1 cannabinoid receptor expression in the striatum: association with corticostriatal circuits and developmental regulation. Front. Pharmacol. 3, 21.

Vinod, K.Y., Sanguino, E., Yalamanchili, R., Manzanares, J., Hungund, B.L., 2008. Manipulation of fatty acid amide hydrolase functional activity alters sensitivity and dependence to ethanol. J. Neurochem. 104 (1), 233-243.

Wang, L., Liu, J., Harvey-White, J., Zimmer, A., Kunos, G., 2003. Endocannabinoid signaling via cannabinoid receptor 1 is involved in ethanol preference and its age-dependent decline in mice. Proc. Natl. Acad. Sci. U. S. A. 100 (3), 1393-1398.

Wenger, T, Gerendai, I, Fezza, F. Gonzalez, S., Bisogno, T., Fernandez-Ruiz, J et al. 2002 The hypothalamic levels of the endocannabinoid, anandamide, peak immediately before the onset of puberty in female rats. Life Sci. 70 (12), 1407-1414. 